\title{
Education, Learning and Freedom
}

\section{GEOFFREY HINCHLIFFE* g.hinchliffe@uea.ac.uk}

This paper takes as its starting point Kant's analysis of freedom in the Critique of Pure Reason. From this analysis, two different types of freedom are discerned, formative and instrumental freedom. The paper suggests that much of what passes for the pedagogy of learning in UK universities takes the form of an instrumental freedom. This, however, involves the neglect of formative freedom - the power to put learning to question. An emancipatory concept of education requires that formative freedom lies at the heart of the educative endeavour, to which learning must be seen as secondary. The proposal of the two types of freedom is based on a relatively detailed consideration of Kant's Critique-this is necessary in order to ensure that the concepts of instrumental and formative freedom have a credible philosophical basis.

\section{*Correspondence: Geoffrey Hinchliffe, Centre for Staff and Educational Development, University of East Anglia,}

Norwich NR4 7TJ, UK. Email: g.hinchliffe@uea.ac.uk

\section{INTRODUCTION}

This paper will attempt to articulate the relationship between education and freedom by exploring the nature of education and differentiating it from learning. However, I do not wish to tread the same path explored by R.S. Peters in his celebrated works of nearly 50 years ago (Peters, 1966). At that time the concern was to develop the conceptual implications of the meaning of the term 'education', especially in regard to its professed intrinsic value. But it seems to me that for us, in the twenty-first century, more incisive tools than conceptual analysis are needed. For one thing, in the mid-twentieth century (certainly in Great Britain) the importance and stature of education and the teaching profession was not something that was under serious challenge. ${ }^{1}$ And for another, Peters did not have to cope with the rise of what is best termed a learning ideology and its concomitant subject, the 'learner'. In contrast to this ideology, this paper seeks to re-establish the emancipatory credentials of education through the use of a conceptual apparatus whose provenance is outside that of 'education' whilst also being firmly philosophical.

It is proposed to make use of Kant's concept of freedom as it arises out of his distinction between the empirical and the intelligible. Thus my focus will be on the first Critique (i.e. the Critique of Pure Reason) rather than his Critique of Practical Reason and the Groundwork of the Metaphysics of Morals. Many scholars in the philosophy of education have undertaken analyses of moral education and moral development using these latter two works as a starting point for their endeavours and have articulated the notion of Kantian autonomy that arises out of the employment of practical reason. ${ }^{2}$ My proposal is to start the analysis further back, as it were, because the analysis of freedom in the first Critique yields much richer fruits, or so I hope to show.

The paper is in three sections. In the first (fairly brief) section I will suggest how learning and education can be distinguished and why it is important to do this. This section will stake out the appropriate conceptual territory in a fairly declarative way and my focus will, by and large, be on education at university level. In the second section I undertake a deeper analysis of Kant's concept of freedom. This will take us into some of the entanglements of Kantian scholarship but I hope to navigate a reasonably clear path-a path which gives some clarity to those from a philosophy of education background without, I hope, straying too far from the bounds

1 For example, in 1964 the Schools Council was set up by a civil servant, Derek Morrell, with the support of the Conservative Minister for Education, Edward Boyle. The Council was designed to influence policy and was teacher led. It was abolished by the Thatcher government in 1983 (see Plaskow, 1985).

2 See, for example, Johnston, 2007; Moran, 2009; Gonza'lez, 2011; and Martin, 2011. 
of acceptability as far as students of Kant are concerned. In the third section, equipped with suitable conceptual tools, I will re-visit and amplify some of the claims made in the first section.

It is my hope to convince readers of the merits of an emancipatory concept of education but even if I do not succeed in doing this I am hopeful that my efforts may contribute to a fresh understanding of what Kant has to offer us today. Too often Kant is discussed (to be then fairly quickly dismissed) as the stern, conservative upholder of Duty underpinned by a categorical imperative that most find to be either problematic or just plain wrong. The Kant I wish to discuss is radical, challenging and, in his range, power and complexity, a philosopher for our times.

\section{EDUCATION AND LEARNING}

There are many forms and contexts of learning and there is no common feature that bind all these together. Learning that a close friend has died, learning how to drive, learning the basic geography of the resort I am holidaying in, learning that Plato's works are far more challenging and problematic than might be surmised from reading the account of justice in the single work The Republic, learning that Polonius in Hamlet may not be a complete fool after all; there is nothing that unites these other than a generic act of 'taking in'. Therefore for the purposes of this paper I will consider the kind of learning that is promoted through pedagogical methods, of varying degrees of rigidity and flexibility. This is the kind of learning that drives schooling in the UK and, at an increasing pace, learning in universities. In particular, I wish to propose that this kind of learning takes the form of a certain cognitive training which itself is a form of disciplining of the self (Foucault, 1980). For one of the crucial components of learning as training is the assumption that any learning has to be assessed, according to which assessment is necessary not simply as a method of confirming what has been learnt; assessment itself is a key part of the learning process, i.e. through undertaking assessment I achieve more learning than I would have done without assessment. The role played by assessment differentiates this cognitive training from other types of learning. For it is clear that assessment is not logically necessary for learning to take place; I may learn many things, including complex knowledge, without ever being assessed. Indeed, many individuals know perfectly well, through their own experience, that learning can take place in this manner.

When the activity of learning as cognitive training is under consideration it is important to understand that no pedagogical method has any more favourable normative value than any other. For example, it makes no difference whether the pedagogy is transmissive or interactive; the only question is which is more effective as evidenced through assessment. The fact that students may favour a more 'learner-centred' approach may commend it simply because their learning may be more successful; but the fact that students willingly co-operate in their own cognitive training through a process of becoming responsible for their own learning does not alter the fact that they are merely actively participating in their own training in exactly the same way that a professional athlete may discuss on a weekly basis changes in her regimen with her personal trainer. Learning becomes a form of training when learning becomes transformed into a series of objectives (outcomes) that must be achieved. I stress again that a learner-orientated approach - the fact that students are employed in peer assessment or in the co-creation of assessment criteria and learning outcomes or in the evaluation of their teachers and tutors-does nothing to detract from the fact they are being trained. If students can be induced to train themselves then so much the better.

A couple of examples of this cognitive training will suffice. In their book Teaching for Quality Learning at University, John Biggs and Catherine Tang introduce the idea of constructive alignment. This means that 'the intended learning outcomes specify the activity that students should engage if they are to achieve the intended outcome as well as the content the activity refers to ... the outcome statement thus specifies a verb that informs students how they are expected to change as a result of learning that topic' (Biggs and Tang, 2011, pp. 97-98). The idea is that not only do learning outcomes drive the learning process, they also drive how something is to be learned by specifying how the learning is to take place. Through this alignment of learning activities with assessment and outcomes, as the authors themselves state, perhaps unwittingly, "the students are "entrapped" in this web of consistency optimising the chance that they will engage appropriate learning activities' (p. 99). Like most modern pedagogues, Biggs and Tang advocate a form of constructivism in which students construct their own knowledge (pp. 22-23) but this means 
nothing if students are obliged to 'construct' knowledge in accordance with learning outcomes laid down in advance. The mental activity of 'construction' is an unknown; nor does it need to be known since all that counts are the achieved outcomes. ${ }^{3}$

Another example of the development of cognitive training schemes is the increasing importance placed on formative feedback. Here, the emphasis is on finely-grained, speedy comments which tell the student exactly what she needs to do to improve her marks next time. The shift in many universities from summative to formative assessment may be supported by reducing the number of exams that students take which, in some cases, may give students and teachers greater freedom; but this is less likely to be the case if the amount of overall assessment increases-for example, where courses are designed with regular assessable learning activities in which feedback is targeted and timely, using so-called 'SMART' criteria. ${ }^{4}$ The role of feedback is emphasised by Graham Gibbs in securing greater student engagement in learning: 'the educational intervention in schools that has more impact on student learning than any other involves improving formative assessment and especially the provision of more, better and faster feedback on student work' (Gibbs, 2010, p. 34). This message is driven home in a later publication aimed at helping universities in the development of their quality assurance documentation. It is recommended that universities record 'how many times in three years students receive feedback on assignments; how many times this is "formative only"; total volume of feedback in words; total volume of one-to-one, face-to-face feedback on assignments, in hours' (Gibbs, 2012, p. 16). ${ }^{5}$

I have taken my two examples from university (higher education) pedagogy deliberately. Schools in the UK have long been subject to learner ideology (it was heralded by the 1988 Education Act). The fact that universities are now subject to a similar regimen shows how extensive is its reach.

There is, of course, nothing inherently 'bad' about cognitive training; indeed, it has much to recommend it for all kinds of socially and economically valuable pragmatic reasons. My point, however, is that it is a diminished form of education. For education designates an activity consisting of the initiation of enquiry in which there is nothing that cannot be put to question. Therefore education must include, as a central component, a critique of all that has been learnt and, indeed, consists in the active dissolution and re-building of learning. The object of educative enquiry could well consist of both the objects of learning-its content - and the process of learning as well. For too much learning may inhibit free enquiry the purpose of which is to disrupt learning. It is one of the paradoxes of education, if not the central paradox, that learning is required, only for that learning to be questioned. But learning by itself subjects nothing to question. Indeed, as we can see, the purpose (unintended or otherwise) of constructive alignment is precisely to close off critique.

The paradox of education should not be seen as a mere 'effect' of an activity engaged in continual self-displacement in the way that post-structuralists might see the 'play' of education and learning. It is not as if in some way learning brings forth education as its other, or that education through its own activity engenders learning, the very thing that undermines it. Despite the attractions of exploring the education/learning duality in this way something is lost if too much is made of it. For it must be remembered that what drives education and is at its very heart is the free agent-radically free if it is the case that anything can be put to question. We can see why it is that learning, as I have described it, is such a threat to education. For the individual learner, entrapped as she is in the web of consistency, cannot be free in any radical sense. Such a person is incapable of putting anything to question at all: such an activity is neither expected nor encouraged. If these were 'normal' times, in which education was not under threat, one might indeed construe the relationship between learning and education as one of play. One might indeed see the individual as taking on the identity of learner on the one hand, and of radical enquirer on the other, with all the enjoyment that the constructing and

3 The book by Biggs and Tang is now in its fourth edition and is prominent in most UK university pedagogic
programmes for academics.

4 Specific, measurable, achievable, realistic, time-bound.

5 Graham Gibbs has been an influential consultant for UK universities for many years. The publisher of the two pamphlets cited, the Higher Education Academy is now subscribed to by almost all UK universities and publications like these are widely read and digested at all levels in many universities in the UK. 
displacing of identities can involve. But these are not normal times: it is the identity of the learner and the activity of learning as cognitive training that dominate. ${ }^{6}$

\section{KANT'S CONCEPT OF FREEDOM}

I have stressed the idea of freedom in relation to education and have suggested earlier that Kant's account is pertinent to this topic. It is to this that I must now turn. Kant's idea of freedom derives from his distinction between the empirical and the intelligible. In the Critique of Pure Reason he says:

\footnotetext{
' $\ldots$ a subject belonging to the sensible world (would) have, first, an empirical world, whereby its actions, as appearances, stand in thoroughgoing connection with other appearances in accordance with unvarying laws of nature ... Secondly, we should also have to allow the subject an intelligible character, by which it is indeed

the cause of those same actions as appearances, but which does not itself stand under any conditions of sensibility, and is not itself appearance' (Kant, 1933,
} A539/B567 p. 468).

Kant goes on to explain that in the capacity of intelligibility, humankind possesses the faculties of reason and understanding and the former (namely reason) enables us to formulate ideas and has its own causality. Thus whereas the understanding is deployed as the essential mechanism for converting appearances into objects, the role of reason is a realm of genuine spontaneity. It is unconditioned and is directed towards the formulation of human ends and the creation of ideas. He explains that freedom is not simply to be viewed 'negatively' as merely independent of empirical conditions because this would mean that it would 'cease to be the cause of appearances'. Consequently, 'it must also be viewed in positive terms, as the power of originating a series of events' and as such can initiate 'a beginning in a series of appearances' (A554/B582, p. 476). This view is reiterated repeatedly: for example, at A548/B576 Kant states that:

'... reason does not follow the order of things as they present themselves in appearance but frames for itself with perfect spontaneity an order of its own according to ideas, to which it adapts empirical conditions and according to which it declares actions to be necessary, even although they have never taken place, and perhaps never will take place'.

This, then, is the famous doctrine of the causality of reason (sometimes also termed by Kant the causality of freedom), a causality that not only generates 'an order of its own' but also 'adapts' empirical conditions to this causality.

Kant's concept of the intelligible, is not, of course, without its problems. Even Kant's early critics professed themselves at a loss to comprehend the bifurcation of the person into what appears to be two selves, the empirical and the intelligible (see Allison, 1990 , p. 29). Yet if these problems can be addressed we have indeed a rich prize: the idea of freedom as the power to initiate events, to formulate ideas and to start new beginnings. I term this kind of freedom 'formative freedom' because it indicates the power not only to set off a causal chain through actions but also the ability to set off causal chains in the realm of ideas. Formative freedom lies at the heart of education since it is this freedom that has the ability or power to put the products of learning to question and to generate and form ideas and perspectives that go beyond learning. It is, I think, worth seeing if the difficulties of Kant's position can be confronted and, if not 'solved' then at least diminished.

If the idea of a causality of reason and its relationship to freedom is not simply to be asserted but argued for, then I think we have little choice but to enter the thickets of Kantian ontology. This may enable a defensible account of freedom to emerge. The implications for education will be picked up again towards the end of this section when the idea of instrumental freedom is introduced.

The first problem that confronts us is Kant's seemingly unswerveable attachment to the idea that the realm of appearances is subject to strict causality. For although Kant insists that reason is 'determining, not determinable' he also insists that 'if we could exhaustively investigate all the appearance's of men's wills, there would not be found a single human action which we could not

6 The rise of the learner has been discussed by Gert Biesta extensively through the use of the term 'learnification'see Biesta, 2010, p. 76 and Biesta, 2010, p. 18-19. I have greatly benefitted from this analysis although when Biesta suggests in his 2010 publication that the rise of learnification may also contain 'emancipatory possibilities ... to the extent that it may empower individuals to take control of their own educational agenda', I frankly doubt this. I pick up on this theme again in the final section of this paper. 
predict with certainty, and recognise as proceeding necessarily from its antecedent conditions' (A550/578). This does seem wholly uncompromising. Kant is not just saying that we could explain empirically all actions/events post hoc; he is also saying that in the realm of appearances we could, in principle, predict with certainty what will happen in the future if we have enough information. What are we to make of this?

One approach is that of Jonathan Bennett, a widely read scholar of Kant, who asks us simply to accept the fact that at this point Kant is being incoherent (Bennett, 1984). One simply cannot reconcile the determinism of the empirical realm with the causality of freedom in the intelligible and this comment might be enough if we were to regard Kant's ideas of antiquarian interest only. But if we wish to see Kant as still having something to say to us then this 'solution' must be a last resort because it would mean that confronted by what appears to be a radical incompatibilism between freedom and causality we are simply to shrug our shoulders.

A different approach to the problem of the apparent disjunction between the two realms would be to maintain that the empirical and the intelligible in effect designate different ontological worlds so that the causality of reason is assigned to the intelligible world and the causality of nature to the empirical world. But whilst this would ensure that events in one world were unaffected by events in the other-so that freedom would play out in an untrammelled way unaffected by the other world (and viceversa) - this metaphysics clearly goes well beyond Kant for whom the question of addressing the role of freedom in a natural world driven by causality was a problem to be addressed, not to be spirited away under the aegis of an implausible metaphysical dualism. ${ }^{7}$

But instead of a duality of 'worlds' one could embrace a duality of perspectives but whose narratives describe and account for objects and events that inhabit the same world. ${ }^{8}$ Thus a promising way of understanding the idea of the intelligible (at least from the standpoint of freedom) involves the realisation that freedom cannot be equated to an object of knowledge. From an epistemological perspective our knowledge of appearances is mediated through the forms of sensibility and through the operation of the understanding by means of the deployment of the categories. But the doctrine of freedom that Kant is proposing is dependent on a switch of perspectives, from the epistemic to the agentic. Thus we can experience the power of our freedom and witness its effects but we cannot know our freedom from the outside. From the agentic perspective, there is nothing corresponding to appearances that helps to establish the possibility of objective knowledge of freedom from an epistemic perspective. Nevertheless it is this agentic capability that ensures we are not subject to empirical causality in the way in which a physical event might be. ${ }^{9}$ Even if, from the empirical perspective (to switch perspectives back to the epistemic) these events can be explained in terms of a causal chain this does not detract from the efficacy of the agentic perspective. What this means, I think, is that although we may well be able to explain events post-hoc, the power of freedom (especially its power to initiate new beginnings) entails that we cannot predict human actions with any reliability.

But what this also means is that we must depart from Kant's hard determinism as outlined in the passage from the Critique, quoted above (A550/B578). If freedom is to make a difference-and the difference I am thinking of here is the power to think differently, the power of dialogue and the ability to change the minds of others as well as oneself - then it must be the case that we have to accept that not all actions and thoughts can be predicted, even if we were in full possession of information. But from this, it need not follow that an empirical cause is not sufficient for its effect. It is not that the actions of agents have the power to override laws established by physics, for example. Nor does it mean that we could not explain in physical terms, actions that have already occurred. It simply means that when it comes to the predictability of actions in physical terms we are prepared to hedge our bets and concede that freedom and hard determinism are not compatible.

This last claim is disputed through a sophisticated piece of reasoning. Thus according to Hud Hudson we can show that freedom and causality of the natural world (in the sense outlined by Kant, i.e. 'hard' determinism) are compatible. There are two strands to his claim. The first concerns an account of human agency along the lines of Donald Davidson's pro-attitude belief model:

7 The 'two worlds' thesis is discussed by Hudson, 1994, pp. 33-34 and by Allison, 1990, Ch. 1 and 3.

8 Discussed by Allison, 1990, p. 43.

9 For instance, the causality outlined in the Second Analogy of the Critique of Pure Reason. 
'Under this model, an agent selects from among alternative means-end relations, furnished by pure or empirical practical reason, the selection being dependent on a belief in the propositional representation of the means to some end which has been conceptualised by the agent and for which the agent has some (rational or sensuous) desire' (Hudson, 1994, p. 42).

The second strand is an affirmation that a free action is 'productive only by being token-token identical to an event that is the effect of some natural cause' (p. 44) by which is meant that mental events are not reducible to physical events but that nonetheless they can be seen as 'tracking' the physical. ${ }^{10}$

We can also see the relationship between these two strands because the belief of the agent is stimulated by some 'cause' in the form of the having of a mental desire which itself can be grounded in the empirical realm (for example, by giving a neurological account of the belief): this gives us the requisite token-token identity.

My objection to Hudson's account is clear: ${ }^{11}$ the kind of freedom outlined here is not the same as the kind of formative freedom which I am concerned to develop in this paper. It is an anaemic, toothless freedom which falls well short of the powers associated with the kind of agent activity that can initiate events and set off new beginnings. It is important to understand that beliefs are not simply propositions related to some desired purpose, for we have beliefs about our beliefs as well. These second order beliefs may provide a broader context in which first order beliefs operate. For example, my beliefs about the relevance of Kant for our times are set against a wider context of beliefs concerning an unwillingness to let go of the narrative of the Enlightenment. This play between first and second order beliefs and their reciprocal interrogation lies at the heart of formative freedom.

A further problem associated with Kant's concept of freedom is his view that the realm of the intelligible is timeless and therefore has no history: "Pure reason, as a purely intelligible faculty, is not subject to the form of time." (Kant, p. 475, A551). Many scholars have commented on the incoherence of this position (Hudson, 1994 and Bennett, 1984 are representative examples) on the grounds that an event cannot be both outside time (qua intelligible) and inside time (qua empirical) at one and the same 'time' because the concept of 'same' is meaningless (in theory the event qua intelligible could occur before or after its empirical counterpart). The 'timeless' thesis is forced on Kant because he is unable to maintain that the realm of the intelligible can be caught up in the sequencing of events that provide the foundation of his analysis of causality in the Second Analogy. Any detailed solution of this problem lies outside the scope of this paper but the starting point would need to be along the following lines: a) free actions are timeless in the sense that they are not subject to empirical succession and causality (otherwise there could never be an initiation of something new), but b) that there is a time order in which agency is subject to succession but not causality. This 'solution' would, in effect, decouple succession in time from causality so that we can say that there are at least some events (i.e. those initiated by free agents) which happen in time but which are underdetermined as far as physical causation is concerned.

Henry Allison (p. 45) suggests that Kant's idea of freedom is regulatory: 'the transcendental idea of freedom ... has a merely regulative, non explanatory function ... by providing a model of deliberative rationality' (e.g. through the use of maxims to guide actions). But in invoking Kant's insights in the development of what I term formative freedom I am suggesting that the regulative function is expanded to include ideas and meanings which transform not only the conceptual landscape but also transform the agent in the process through the development (and discarding) of beliefs. Being free involves the ability to transform one's own beliefs and to calibrate these beliefs both through empirical testing and through dialogue with others. Thus we grant that although agent activity is enmeshed and entangled with the empirical it is still transcendental in the sense that the agent projects possibilities that are formulated conditional on what is given at any moment but that these givens include the agent's own beliefs which, through agentic reflective activity are subject to transformation.

Thus far I have discussed what I term 'formative freedom'. But Kant also suggests that there is another kind of freedom, different but related to the freedom associated with the causality of reason. This conception is more straightforward and familiar. In the 'Canon of Pure Reason' in the Critique Kant distinguishes between beings whose actions are necessitated by sensuous impulses and those (such as humans) that are merely pathologically affected by sensuous impulses (but not actually necessitated). He goes on to say:

10 Hudson is drawing on features of Davidson's account of anomalous monism (see Davidson, 1980).

\section{Although I should make it clear that I have benefitted greatly from his book.}


We have the power to overcome the impressions on our faculty of sensuous desire, by calling up representations of what, in a more direct manner, is useful or injurious. But these considerations, as to what is desirable in respect of our whole state, that is, as to what is good or useful, are based on reason' (A802/B830, p. 633).

This is often termed practical freedom as opposed to transcendental freedom because the agent is guided by perceptions of what seems good or useful (see, for example, Allison, 1990, p. 207) Since choices need to be made and reason is employed in framing what could be useful in the light of desires (that may be conflicting) then freedom is still involved; but the kind of creative activity associated with transcendental freedom (i.e. what I have termed formative freedom) is lacking. This kind of freedom is recognisably 'instrumental' in that given certain ends, the agent works out the best means to attain them. But the ends themselves may be taken as 'givens' which it is beyond the capacity of instrumental freedom to call into question; for this is the task of formative freedom. It should be emphasised that instrumental freedom still requires actions that are voluntary despite its restricted scope. Hence it is, of course, possible to abrogate instrumental freedom through direct coercion by forcing someone to undertake actions and behaviours that are alleged to be in their interests or against those interests, as the case may be.

\section{THE ROLE OF FREEDOM IN EDUCATION AND LEARNING}

I have already suggested that it is formative freedom that lies at the heart of education and it will be seen that it is instrumental freedom that drives learning (cognitive training) as I have described it in the first section. For assuredly, this learning can only be effective if it is undertaken voluntarily and if this voluntariness characterises every stage. There is little prospect of training — of encouraging the appropriate kind of cognitive behaviours - if the principle driver is coercion. But note how the learning process sets up proxy goals, through the deployment of learning outcomes and the ends of assessment, of Kantian practical freedom (what I term instrumental freedom) along the lines of useful and satisfying ends, analogous to the goals furnished through desires and wants. The learning process itself sets up these behaviours with the expectation that the instrumental freedom of learners will, in varying degrees, fulfil through voluntary actions the required achievements. But note also that those who choose not to exercise their instrumental freedom risk - nay, guarantee - the stigma of failure. The desire to avoid failure and what is nearly as badunder-achievement - can usually be relied on to ensure that learners exercise their instrumental freedom in order to achieve the goals prescribed for them.

By contrast, formative freedom - which drives educational activity - takes failure in its stride. It recognises that freedom involves the freedom to fail. In the first section it was suggested that education can be characterised as that which puts learning to question. But this is only one side of formative freedom. Through the causality of reason new ideas and perspectives are generated on the basis of this critique; but since those ideas are themselves put to question then the likelihood of 'failure' is always present. New ideas and perspectives are never valid merely because they are innovative. But the idea that failure is to be welcomed is entirely foreign to the process of learning (for example, it is hugely feared by students), construed as cognitive training. And because the process of learning eschews critique it is always vulnerable to whatever claim to innovation comes along. Since learning never puts itself to question the 'what' to be learned can become entirely arbitrary. Learning is equally at home with the comforting truths of disciplinary knowingness as it is with the latest claims to 'new' knowledge (often garnered from the internet). Gradually the process of learning itself starts to assume a dominance over the 'what' is learnt. As mere content, the latter falls away, to be displaced by the endless monotony of busy tasks which are designed to fill time and to justify the existence of those enmeshed in its machinery.

I mentioned earlier that there are different ways of learning (e.g. informal learning) and not all learning takes the form of cognitive training. For example, there is that venerable form of learning-learning as scholarship — which is different from cognitive training in this respect: the practice of scholarship is characterised by a self-effacement in which the ego of the scholar is placed at the service of scholarly discoveries and disquisitions (thus scholarship is not learner-centred). Whilst its high point in Europe was perhaps several hundred years ago (i.e. the revival of classical humanism in the $15^{\text {th }}$ and $16^{\text {th }}$ centuries $^{12}$ ) it has, of course never

\footnotetext{
12 Stephen Greenblatt's The Swerve contains a fascinating account of the discovery of the manuscript of Lucretius's De Rerum Naturae in 1417 by Poggio Bracciolini. Yet Greenblatt as well as bringing to our attention the indefatigability and heroism of this Renaissance scholar also shows us his creative limitations as well-the limitations inherent in learning.
} 
disappeared. By contrast, the learning that takes the form of training naturally places the learner at the centre of the process and rightly so, because it is she who is being shaped, moulded and groomed through a process akin to dressage. ${ }^{13}$

At this point a protest may be raised: in life outside of educational processes, our conduct typically can be characterised in terms of both instrumental and formative freedom; surely education is similarly characterised by the judicious combination of both types of freedom as well. To which my answer is: not quite. I agree that educational processes will include elements of learningnot only scholarly learning but also cognitive training. But I insist that both types of learning (as species of instrumental freedom) must be subordinated to formative freedom, to education as critique.

We get a clear, unalloyed statement of what is needed, I think, in Kant's short pamphlet, What is Enlightenment? published in 1784, in which he pronounces that 'Enlightenment is man's emergence from his self-incurred immaturity' (Kant, 1970, p. 54). The essential passages in Kant are well worth quoting in full because I think that in these conservative times it is easy to forget what we, as teachers, are about:

Enlightenment is man's release from his self-incurred tutelage. Tutelage is man's inability to make use of his understanding without direction from another. Selfincurred is this tutelage when its cause lies not in lack of reason but in lack of resolution and courage to use it without direction from another. Sapere aude! "Have courage to use your own reason!" - that is the motto of enlightenment ... For this enlightenment, however, nothing is required but freedom, and is indeed the most harmless among all the things to which this term can properly be applied. It is the freedom to make public use of one's reason at every point. But I hear on all sides,

"Do not argue!" The Officer says: "Do not argue but drill!” The tax collector: "Do not argue but pay!" The cleric: "Do not argue but believe!" ... Everywhere there is restriction on freedom (Kant, 1970, p. 54-55).

Kant goes on to emphasise the intrinsic relationship between freedom and its deployment in public space:

... the freedom to make public use of one's freedom in all matters ... the public use of man's freedom must always be free and it alone can bring enlightenment among men (Kant, 1970, p. 55).

If we were to take Kant seriously today, what would the educational landscape in higher education look like? I suggest the following possibilities:

1. There would be greater emphasis on the creativity of ideas and students (and academics) would see their role less in terms of private learning and much more in terms of public critique. For example, they might worry less about the apparatus of academic scholarship. I have myself seen students hampered and cramped by the perceived requirement that every written statement and assertion must be backed by a scholarly reference. This tyranny of learning inhibits students from expressing their own opinions; indeed, it encourages a fear of speaking out in the absence of supposed scholarly back-up.

2. When student work is assessed, learning outcomes act only as a guide. Assessment that is driven by learning outcomes will be discouraged as mean, limiting and disrespectful to the student in respect of her formative freedom - her freedom to critique learning, including learning outcomes.

3. Students will no longer be referred to a 'learners' but will only be referred to as students (or better, as participants) understood as co-investigators with their tutors into disciplinary understanding. The learner culture will be displaced by a culture in which tutors welcome their students as co-participants into a shared practice of learning, investigation and creation.

4. A key ingredient of formative freedom is the role of judgement and students will be introduced to the nature of academic judgement early on. They will learn that the creation of ideas is driven by judgements which identify deficits or inadequacies in theories, interpretations and evidence; and they will learn also that judgements are nearly always provisional and often wrong. ${ }^{14}$ But, in addition,

13 See Foucault, 1980 for the use of this term in respect of 'disciplining' the self.

14 I am well aware that the business of academic judgement requires another paper on its own. 
students will learn that judgements themselves may be more or less informed, taking into account normative considerations as well as the deliverances of disciplinary knowledge. They will learn how to recognise poor judgement and how to make their own judgements as well.

Of these four features it is perhaps the last one that has the most importance - the centrality of judgement in the academic process. This contributes to the growth not of a learner culture in which the focus is on the learner but a culture of education in which neither student not tutor is privileged but where both work together, as free spirits.

\section{NOTES}

\section{REFERENCES}

<bib id="bib1" label="Allison, 1990" type="Book">Allison, H. E. (1990) Kant's Theory of Freedom (Cambridge, Cambridge University Press).</bib>

<bib id="bib2" label="Bennett, 1984" type="Book">Bennett, J. (1984) Commentary: Kant's Theory of Freedom, in: A.W.Woodi (ed.), Self and Nature in Kant's Philosophy (Ithaca, NY, Cornell University Press), pp. 102--112.</bib>

<bib id="bib3" label="Biesta, 2015" type="Periodical">Biesta, G. (2015) What is Education for? On Good Education, Teacher Judgement, and Educational Professionalism, European Journal of Education, Vol. 50, No. 1, pp. 75-87. </bib>

<bib id="bib4" label="Biesta, 2010" type="Book">Biesta, G. (2010) Good Education in an Age of Measurement (Boulder, CO, Paradigm Publishers).</bib>

<bib id="bib5" label="Biggs and Tang, 2011" type="Book">Biggs, J. and Tang, C. (2011) Teaching for Quality Learning at University (Maidenhead, Open University Press).</bib>

<bib id="bib6" label="Davidson, 1980" type="Book">Davidson, D. (1980) Mental Events, in: Davidson, Di. Essays on Actions and Events (Oxford, Oxford University Press).</bib>

<bib id="bib7" label="Foucault, 1980" type="Book">Foucault, M. (1980) The Eye of Power, in: C.. Jordan (ed.) Power/Knowledge (New York, Pantheon Books), pp. 146--165.</bib>

<bib id="bib8" label="Gibbs, 2010" type="Book"> Gibbs, G. (2010) Dimensions of Quality (York, Higher Education Academy). $</$ bib $>$

<bib id="bib9" label="Gibbs, 2012" type="Book">Gibbs, G. (2012) Implications of 'Dimensions of Quality' in a Market Environment (York, Higher Education Academy).</bib>

<bib id="bib10" label="Gonza'lez, 2011" type="Periodical">Gonza'lez, A. M. (2011) 'Kant's Philosophy of Education: Between Relational and Systemic Approaches, Journal of Philosophy of Education, Vol. 45, No. 3, pp. 433$-454 .</ b i b>$

<bib id="bib11" label="Greenblatt, 2011" type="Book"> Greenblatt, S. (2011) The Swerve (London, The Bodley Head). $</$ bib $>$

<bib id="bib12" label="Hand, 2006" type="Periodical"> Hand, M. (2006) Against Autonomy as an Educational Aim, Oxford Review of Education, Vol. 32, No. 4, pp. 535--550.</bib> 
<bib id="bib13" label="Hudson, 1994" type="Book">Hudson, H. (1994) Kant’s Incompatibilism (Ithaca, NY, Cornell University Press). </bib >

<bib id="bib14" label="Johnston, 2007" type="Periodical"> Johnston, J.S. (2007) Moral Law and Moral Education: Defending Kantian Autonomy, Journal of Philosophy of Education, Vol. 41, No. 2, pp. 233--245.</bib>

<bib id="bib15" label="Kant, 1933" type="Book">Kant, I] (1933) Critique of Pure Reason, trans. N. Kemp-Smith (London, Macmillan).</bib>

<bib id="bib16" label="Kant, 1970" type="Book">Kant, I. (1970) Kant’s Political Writings, trans. H. Reiss (Cambridge, Cambridge University Press), pp. 54--60.</bib>

<bib id="bib17" label="Martin, 2011" type="Periodical">Martin, C. (2011) Education without Moral Worth? Kantian Moral Theory and the Obligation to Educate Others, Journal of Philosophy of Education, Vol. 45, No. 3, pp. 275492.</bib>

<bib id="bib18" label="Moran, 2009" type="Periodical">Moran, K.A. (2009) Can Kant Have an Account of Moral Education? Journal of Philosophy of Education, Vol. 43, No. 4, pp. 471--484.</bib>

<bib id="bib19" label="Peters, 1966" type="Book">Peters, R.S. (1966) Ethics and Education (London, George Allen and Unwin). $</$ bib $>$

<bib id="bib20" label="Plaskow, 1985" type="Book">Plaskow, M. (1985) The Life and Death of the Schools Council (London, Taylor and Francis).</bib>

<bib id="bib21" label="Wood, 1984" type="Book">Wood, Allen W. (ed.) (1984) Self and Nature in Kant's Philosophy (Ithaca, NY, Cornell University Press). </bib> 